\title{
New technologies in the use of exhaled breath analysis for biological monitoring
}

\author{
H K Wilson, A C Monster
}

\begin{abstract}
Breath analysis is an attractive noninvasive procedure for screening workers exposed to solvents. It has been used in numerous laboratory based studies and for field research. Despite the obvious advantages in routine biological monitoring it has failed to become widely accepted as a tool in occupational hygiene. Recent advances in breath sampling and analysis are such that it is likely to become more widely used in the future. In this paper, the past 5 years have been reviewed to try to assess what developments might now contribute to the increased use of breath analysis in biological monitoring; in particular, the development of a selected ion flow tube mass spectrometer for real time direct analysis of trace gases in breath and the more immediately available and less expensive indirect methods involving collection devices with adsorbent tubes is important. The introduction of guidance values for biological monitoring with clear advice on sampling times and the recognition of the importance of quality assurance programmes will help improve confidence in the technique.

(Occup Environ Med 1999;56:753-757)
\end{abstract}

Keywords: breath analysis; technology; biological monitoring

Breath sampling and analysis is superficially an attractive technique for biological monitoring. It has been used widely over the past 20 years in studies in the occupational and environmental area primarily as a research tool. Much of the fundamental work on the validation of breath sampling and the relevant toxicokinetic data was established many years ago by Astrand, ${ }^{1}$ Stewart et al, ${ }^{2}$ Droz and Guillemin, ${ }^{3}$ and Monster et $a l .{ }^{4}$ Breath analysis has not yet found its way into routine biological monitoring programmes, possibly because there are no commercially available breath samplers or because the data generated are difficult to interpret. Recent technical developments would tend to indicate the imminent use of routine breath analysis for biological monitoring of workers exposed to solvents. This view is further strengthened by the need to move away from blood sampling towards non-invasive biological monitoring procedures and the decision by some authorities to set biological monitoring guidance values. Various kinds of breath samples have been used, including mixed expired air and end expired air. Most authors prefer the use of end expired air, after breath holding, which is assumed to have achieved equilibrium with blood in the pulmonary capillaries. Hence most techniques for breath analysis have been designed to capture and analyse end expired samples as surrogates for blood samples.

Recent developments in breath analysis can be classified as (a) direct reading (real time) methods which usually involve complex instrumentation such as mass spectrometry, or (b) indirect methods which capture the breath sample so that it is ready for analysis by an appropriate technique - for example, gas chromatography.

There are obvious advantages in having immediate results produced on site by instruments that can be read directly; however, these techniques need to be portable, robust, easy to use, and affordable. The less expensive and alternative approach of capturing the breath sample and then transferring it to the laboratory for analysis is more likely to be adopted by occupational health professionals as a practical tool in exposure assessment.

For practical purposes the use of breath analysis in biological monitoring should be easy to use in field studies, be non-invasive, and be acceptable to workers. A sampling device must:

- Collect a valid sample (end expired air)

- Be easy to collect (low respiratory resistance)

- Be able to handle high water content

- Maintain sample integrity (no loss of analyte or contamination of sample)

- Be compatible with a suitable analytical technique

- Be robust and reproducible

- Be safe and hygienic

- Be inexpensive

- Produce results which can be interpreted.

Many of these conditions apply equally in the case of instruments that can be read directly but certain other considerations need to be taken into account. The instrument must:

- Have an inlet system which samples end expired air

- Be sufficiently sensitive and specific

- Have a rapid response and recovery time

- Be unaffected by high water vapour content.

The physiological basis of breath analysis has been reviewed and a description of various sampling devices and direct methods of analysis have been reported previously by Wilson, ${ }^{5}$ and more recently Wallace et $a l^{6}$ reviewed measurements of volatile organic compounds in breath. In this critical review we confine ourselves to work which has been reported on 
the use of breath sampling and analysis in the past 5 years.

\section{Instruments for direct reading}

The most versatile direct technique for real time analysis of trace compounds in breath is mass spectrometry. Most mass spectrometers are now quadrupole instruments and there has been a tendency to move from electron impact ionisation to chemical ionisation. Atmospheric pressure ionisation mass spectrometers have been around for over 20 years and have been used for real time breath analysis.

Recently, soft ionisation techniques-such as proton transfer reaction mass spectrometryhave been used for breath analysis. These techniques are quantitative, not affected by water vapour, and the spectra are relatively easy to interpret.

SELECTED ION FLOW TUBE ANALYSIS

Smith and Spanel ${ }^{7}$ reported the use of the selected ion flow tube technique (SIFT), which is a form of chemical ionisation mass spectrometry for real time trace gas measurement in breath. This method relies on the soft ionisation of trace gases with an appropriate precursor ion species - for example, protonated water $\mathrm{H}_{3} \mathrm{O}^{+}$. Primary positive ions are created in a microwave discharge ion source, and are separated with a quadrupole mass filter and injected into a helium gas stream. The ions are carried along a flow tube and sampled through a pinhole into a quadrupole mass spectrometer. After the sample of breath enters the tube through a heated inlet port the trace gas in the sample interacts with the primary ions. The product ions of these ion molecule reactions are detected producing the resulting mass spectrum. The response time is about $20 \mathrm{~ms}$ and hence it is possible to observe real time fluctuations in trace gas concentrations. The technique is able to measure down to $10 \mathrm{ppb}$ and can display the simultaneous partial pressure time profiles of breath-for example, of acetone, isoprene, ammonia, and methanol. With oxygen precursor ions $\left(\mathrm{O}_{2}^{+}\right)$perchloroethylene was detected in breath 16 hours after exposure. ${ }^{8}$ These researchers have built a transportable SIFT mass spectrometer and think that a portable device based on the same technology is feasible.

\section{PROTON TRANSFER REACTION MASS}

SPECTROMETRY

Lindinger et $a l^{9}$ have used similar technology called proton transfer reaction mass spectrometry, to measure mixtures of volatile organic compounds at ppt concentrations in breath. They have shown the versatility of the technique by detecting diallyl sulphide, diallyl disulphide, and allyl methyl disulphide in garlic breath and have followed breath concentrations of acetone and propan-2-ol in volunteers who had received an oral and an intravenous dose of propan-2-ol. In studies in children and adults they were able to show significant differences in isoprene concentrations in breath.
ELECTROCHEMICAL DEVICES

Electrochemical devices have been used for many years for measurements of alcohol in breath and more recently for determining carbon monoxide in breath. Vreman et $a l^{10}$ describe the evaluation of a fully automated end tidal carbon monoxide instrument for breath analysis. The technique involves sampling breath through a nasal catheter directly into an electrochemical detector. The instrument automatically measures carbon monoxide (and carbon dioxide for ensuring a valid end tidal sample). This complex device is directed at clinical applications rather than workplace screening. Commercially available analysers are used by smoking clinics and can be used in the occupational setting. The United Kingdom Health and Safety Executive has set for the first time, a health based biological monitoring guidance value of $30 \mathrm{ppm}$ for carbon monoxide in breath. ${ }^{11}$

DIODE LASERS

A multicomponent gas analyser based on tunable diode lasers has been used in the real time measurement of some endogenous gases in breath at the ppb level. ${ }^{12}$ The system uses lead salt tunable diode lasers of different spectral regions from $4 \mu \mathrm{m}$ to $12 \mu \mathrm{m}$ that operate at liquid nitrogen temperatures. The technique might have applications in the biomedical area for the simultaneous detection of gases such as $\mathrm{CO}, \mathrm{NH}_{3}$, and NO. It is less clear the extent to which the technique could be more widely used for the detection of environmental and workplace pollutants.

\section{IMMUNOASSAY}

Lukens ${ }^{13}$ gives brief details of the detection of caffeine in breath with an immunoassay film badge. The badge system consists of an indium semimirror to which is attached a monolayer of anticaffiene antibody. The badge seems to be capable of functioning at about ambient temperatures and at high humidity. Samples of breath from a coffee drinker were passed across the badge and a signal for caffeine was detected in $<5$ seconds. Further work on this approach will determine whether the technique is applicable for routine monitoring.

\section{Indirect methods}

The use of indirect methods generally involves collecting and trapping the breath sample and subsequently transferring it to an analytical instrument for analysis. Devices used have included glass tubes, bags, canisters, adsorbent tubes, and cryogenic traps. For most practical applications the devices have been designed to trap the end expired sample.

\section{FLOW THROUGH SAMPLES AND ADSORPTION} TUBES

Ljungkvist and Nordlinder ${ }^{14}$ described a field method for the sampling and analysis of benzene in end expired air. The sampling device consisted of a modified peak flow meter to which was attached a plastic tube, a temperature sensor, and a glass adsorbent tube packed with Tenax. The subject breathed 


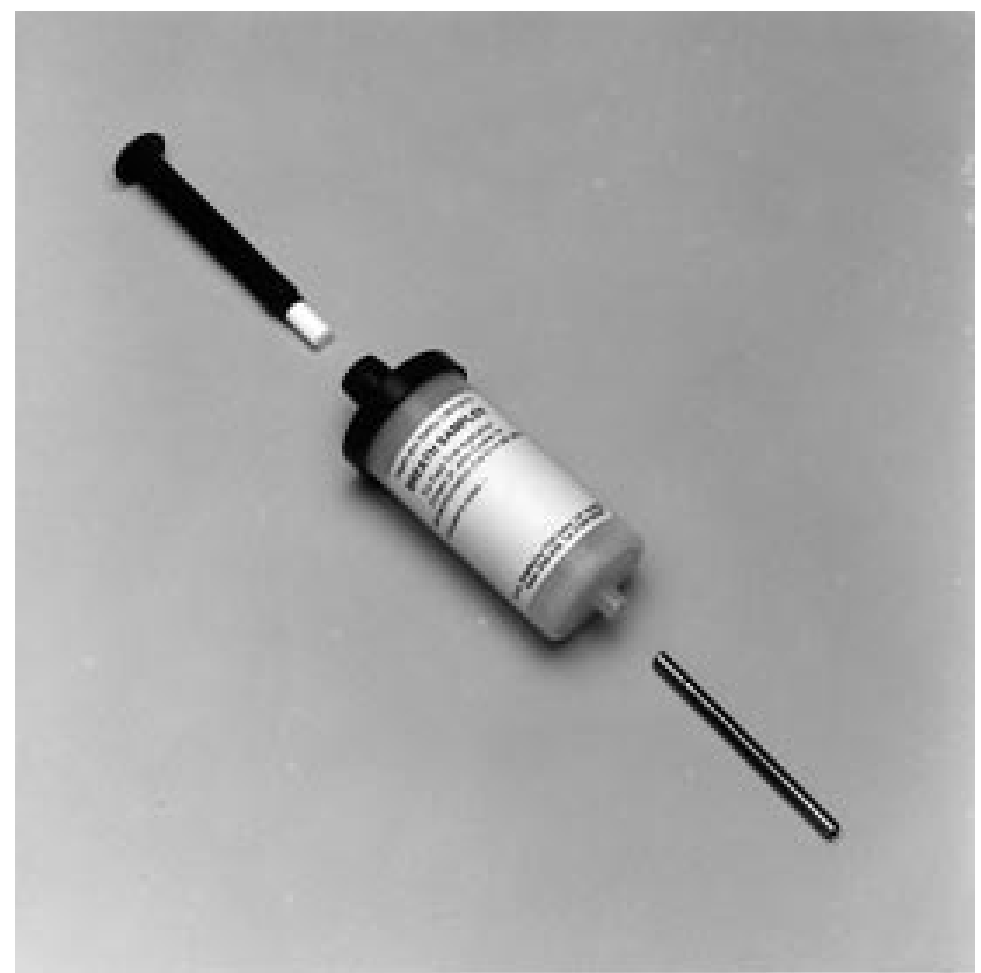

Figure 1 New preproduction device based on a syringe made from an inert plastic and fitted with a one way valve piston.

through the flow meter and when the temperature reached $34.5^{\circ} \mathrm{C}$, indicating that an end expired sample had been delivered, a $100 \mathrm{ml}$ sample was drawn through the adsorbent tube with a manual sampling pump. The sample was thermally desorbed into a cyrotrap and then analysed by gas chromatography. The benzene detection limit in breath was $0.5 \mu \mathrm{g} / \mathrm{m}^{3}$.

Prado et $a l^{15}$ developed a similar device for monitoring isoflurane in breath, which consisted of an aluminium tube modified to concentrate samples of end expired air from one or more exhalations on to a thermal desorption tube. A servomotor driven gas syringe $(50 \mathrm{ml})$ draws a sample from the heated tube and then dispenses it on to an adsorbent tube packed with Chromosorb 106. Samples of exhaled air were obtained with the subject holding their breath for 10-15 seconds, then exhaling. The total volume passed through the adsorbent tube was 11 of end expired air, representing five $200 \mathrm{ml}$ aliquots from each of five consecutive expirations. The adsorbent tubes were thermally desorbed into a gas chromatograph with flame ionisation detection. After measuring breath isoflurane in 167 medical staff, the authors calculated a biological exposure index for breath isoflurane which corresponds to air standards.

Dyne et $a l^{16}$ reported a simple sampling device based on a variation of the HaldanePriestly tube principle whereby the final portion of breath is held within a tube, then transferred to an adsorbent tube. The breath sampler consists of an aluminium sampler narrowed at one end to form a mouthpiece and at the other end to form an adapter which accepts automated thermal desorption tubes. Inside the sampler casing is a collapsible Tedlar sam- pling bag $(85 \mathrm{ml})$ which is attached to a moveable brass ring which is guided down the length of the sampler by two open channels. At either end are two non-return valves, one of which is also attached to the brass ring. The worker breathes through the sampler until the final portion of breath that has been exhaled is trapped within the sampler. An absorption tube is then attached to the end of the sampler and by moving the brass ring and the non-return valve down the sampler, the captured breath is forced out of the sampling bag and is transferred on to the absorption tube. The absorption tube is then sealed and stored until ready for analysis by gas chromatography-mass spectrometry. Further developments of this principle have led to a new preproduction device based on a syringe made from an inert plastic and fitted with a one way valve piston (fig 1). ${ }^{17}$ The worker blows through the sampler syringe and the last portion of breath is retained in the sampler (volume $140 \mathrm{ml}$ ). The sample is then transferred by pushing the piston, onto an absorbent tube ready for automated thermal desorption followed by gas chromatography. The sampler operates with a $94 \%$ transfer efficiency with no significant loss of analyte or contamination. Tenax, which repels water vapour, is a suitable absorbent for non-polar solvents, and the use of 35/60 mesh size minimises back pressure when delivering the sample to the tube. The sampler has been extensively field tested in several industries. This procedure is particularly useful for exposure to multiple solvents or for investigating short term high exposures or long term low exposures. The sampler and its operation have been described in the trade press. $^{18}$

FLOW THROUGH SAMPLES WITH GAS SYRINGE INJECTION

Stein et $a l^{19}$ measured halogenated hydrocarbons in breath samples. They collected samples in $40 \mathrm{ml}$ glass silanised tapered tubes with a shut off valve and a rubber septum for withdrawing the sample. Samples were withdrawn with a gas syringe and injected onto a gas chromatograph fitted with an electron capture detector. The authors report that the analyses were stable for at least 22 days in these tubes. A similar method was used to collect alveolar air samples from swimmers, exposed to trihalomethanes in swimming pools, who blew through glass tubes $\left(34 \mathrm{~cm}^{3}\right)$ with two valves. ${ }^{20}$ At the end of expiration the valves were closed. The tubes were heated to $37^{\circ} \mathrm{C}$ before gas samples were removed and injected into a gas chromatograph-mass spectrometer. Chloroform, bromodichloromethane, and dibromochloromethane were detected in the breath of swimmers. An example of the glass tube breath sampler is shown in figure 2 .

\section{EVACUATED CANISTERS}

A single breath canister technique was used by Pleil and Lindstrom. ${ }^{21}$ The sampling apparatus consists of an evacuated stainless steel 11 canister fitted with a small Teflon tube used as a mouthpiece. The subject is instructed to 


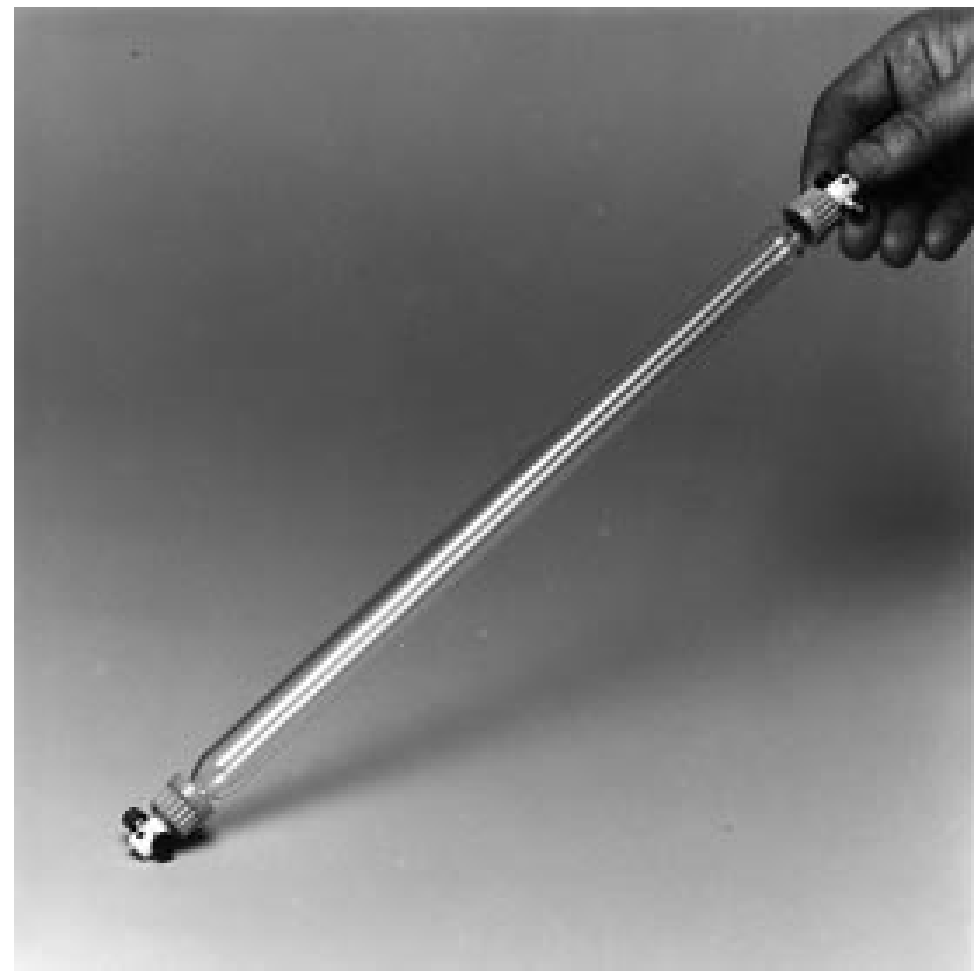

Figure 2 Glass tube breath sampler.

collect a sample at the end of a normal breath. The analytical instrumentation is fully automated to extract an aliquot from the canister and transfer it to a cryogenic trap and then thermally desorb the sample into a capillary column followed by mass spectrometric analysis. This technique requires that subjects are trained to provide end expired samples.

GAS SAMPLING BAGS

Franzblau et $a l^{2}$ collected breath for methanol analysis through a $\mathrm{T}$ mouthpiece fitted with a $500 \mathrm{ml}$ trapping bag and a $500 \mathrm{ml}$ aluminised Mylar sample bag. The sample bag was fitted with a one way valve and a gas sampling port. After breath holding for 10 seconds the first $500 \mathrm{ml}$ filled the trapping bag which, when filled, triggered the opening of the valve on the sampling bag. This bag then contained the end expired portion of air. The methanol content was analysed by infrared Fourier transform infrared, and carbon dioxide was also measured to validate the end expired sample. The samples were reported to be stable for at least 2 days. This technique may have limited applications in field monitoring. The stability of individual substances in the sampling bags and the specificity of the analytical technique need to be established.

MICROSENSOR ARRAY ANALYSIS

Groves and Zellers ${ }^{23}$ described a prototype portable microsensor array instrument capable of selectively measuring three chlorinated solvents in breath at concentrations of $<1 \mathrm{ppm}$. Breath samples were collected in Tedlar bags and transferred to Tenax adsorbent tubes. The samples were then thermally desorbed onto the instrument which uses an array of four polymer coated surface acoustic wave resonators. Sensor responses are based on the reversible changes in the mass and viscoelasticity of the polymeric coatings after vapour absorption. Compensation for high sample humidity was achieved with baseline subtraction. Further work will be required to determine whether this technology can be adapted for field use.

\section{Discussion}

Breath analysis will be readily accepted for routine screening when it is reliable, robust, and inexpensive. Such is the case with measurements of alcohol in breath when they are used for evidential purposes. In the case of alcohol, we are dealing with a single substance at a relatively high concentration and for which there are suitable analytical methods. Also, there are well validated data sets which assist with the interpretation of results. In the occupational and environmental setting the position is much less well established. There are numerous pollutants on people's breath and the concentrations are orders of magnitude less than those of alcohol. Although the relevant toxicokinetic data of many volatile compounds are well known, the relations between the breath concentration, the time after exposure, and the exposure conditions are

Devices for exhaled breath analysis

\begin{tabular}{|c|c|c|c|c|c|c|}
\hline Device & Sampling and analysis & Application & Detection limit & Ease of use & Availability & Reference \\
\hline $\begin{array}{l}\text { Modified peak flow } \\
\text { meter }(100 \mathrm{ml})\end{array}$ & $\begin{array}{l}\text { Manual pump with adsorbent tube (Tenax) } \\
\text { Thermal desorption } \\
\text { Gas chromatography }\end{array}$ & Benzene & $0.5 \mu \mathrm{g} / \mathrm{m}^{3}$ & Simple & $\begin{array}{l}\text { Custom } \\
\text { made }\end{array}$ & 14 \\
\hline Aluminium tube $(50 \mathrm{ml})$ & $\begin{array}{l}\text { Automatic pump with adsorbent tube } \\
\text { (Chromosorb 106) } \\
\text { Automated thermal desorption } \\
\text { Gas chromatography }\end{array}$ & Isoflurane & Not reported & Simple & $\begin{array}{l}\text { Custom } \\
\text { made }\end{array}$ & 15 \\
\hline $\begin{array}{l}\text { Aluminium tube with } \\
\text { inner collapsable } \\
\text { Tedlar bag }(85 \mathrm{ml})\end{array}$ & $\begin{array}{l}\text { Manual piston with adsorbent tube (Tenax) } \\
\text { Automated thermal desorption } \\
\text { Gas chromatography }\end{array}$ & Mixed solvents & Typically $1 \mathrm{nmol} / 1$ & Simple & $\begin{array}{l}\text { Custom } \\
\text { made } \\
\text { prototype }\end{array}$ & 16 \\
\hline $\begin{array}{l}\text { Inert plastic syringe with } \\
\text { valve }(140 \mathrm{ml})\end{array}$ & $\begin{array}{l}\text { Manual piston with adsorbent tube (Tenax) } \\
\text { Automated thermal desorption } \\
\text { Gas chromatography }\end{array}$ & Mixed solvents & Typically $1 \mathrm{nmol} / 1$ & Simple & $\begin{array}{l}\text { Commercially } \\
\text { available }\end{array}$ & 18 \\
\hline $\begin{array}{l}\text { Glass tube silanised ( } 40 \\
\mathrm{ml} \text { ) }\end{array}$ & $\begin{array}{l}\text { Reheated - Gas-tight syringe } \\
\text { Gas chromatography } \\
\text { Mass spectrometry }\end{array}$ & $\begin{array}{l}\text { Halogenated } \\
\text { hydrocarbons }\end{array}$ & Typically $\mu \mathrm{g} / \mathrm{m}^{3}$ range & Simple & $\begin{array}{l}\text { Commercially } \\
\text { available }\end{array}$ & $\begin{array}{l}19 \\
20\end{array}$ \\
\hline Mylar bag $(500 \mathrm{ml})$ & $\begin{array}{l}\text { Reheated cell } \\
\text { Fourier transform infrared }\end{array}$ & $\begin{array}{l}\text { Methanol and } \\
\text { carbon dioxide }\end{array}$ & $\begin{array}{l}\text { Ethanol } 0.5 \mathrm{ppm} \\
\mathrm{CO}_{2} 0.2 \%\end{array}$ & Moderate & $\begin{array}{l}\text { Commercially } \\
\text { available }\end{array}$ & 22 \\
\hline $\begin{array}{l}\text { Evacuated SUMMA } \\
\text { canister }\left(\begin{array}{ll}1 & 1\end{array}\right)\end{array}$ & $\begin{array}{l}\text { Pressurised vessel and cryogenic trap } \\
\text { Gas chromatography } \\
\text { Mass spectrometry }\end{array}$ & $\begin{array}{l}\text { Halogenated } \\
\text { hydrocarbons }\end{array}$ & Not reported & Moderate & $\begin{array}{l}\text { Commercially } \\
\text { available }\end{array}$ & 21 \\
\hline
\end{tabular}


not always well established and the significance of individual variability has not yet been studied sufficiently. To date there are no widely accepted commercially available procedures for breath analysis. There are indications that in recent years we have made some progress. Instruments for direct reading based on mass spectrometry may become available, but they will be relatively expensive. Further developments with microsensor arrays or immunoassay technology may possibly result in cheaper direct reading options. Alternatively, there seems to be general agreement that the use of absorbent tubes is a useful method for trapping and maintaining the integrity of breath components. They have wide applicability because of the variety of selective absorbents which are available. The technique uses widely available automated thermal desorption technology combined with gas chromatography. The commercial availablity of devices such as the syringe sampler which seems to have the required simplicity and reliability will help promote the use of breath analysis for routine field use. Some general findings on various devices reported in this review are summarised in the table.

There are well established national and international quality assurance schemes in biological monitoring. At the present time these do not extend to breath analysis. In the case of evidential testing of alcohol in breath, quality assurance schemes have been put in place. ${ }^{24}$ These programmes cover preparation of the subject, the analysis process, reporting results, proficiency testing, inspections, and training issues. An equivalent programme for the application of breath analysis in biological monitoring would be advantageous.

Further progress will also be made when breath sampling results can be put in context and interpreted. Progress has been made in this area with the introduction of some biological exposure values such as biological exposure indices for perchloroethylene and carbon monoxide, ${ }^{25}$ biological tolerance values for carbon tetrachloride, perchloroethylene, and 1,1,1-trichloroethane, ${ }^{26}$ and a biological monitoring guidance value for exposure to carbon monoxide. ${ }^{11}$

In conclusion, the use of suitable breath sampling and analysis procedures and the adoption of appropriate sampling strategies will make a major contribution to the biological monitoring of exposure to solvents.
1 Astrand I. Uptake of solvents in the blood and tissues of man. Scand $\mathcal{f}$ Work Environ Health 1975;1:347-54.

2 Steward RD, Hake CL, Peterson JE. Use of breath analysis to monitor trichloroethylene exposure. Arch Environ Health 1974;29:6-13.

3 Droz PO, Guillemin MP. Occupational exposure monitoring using breath analysis. $\mathcal{F}$ Occupational Medicine 1986;28: 593-602.

4 Monster AC, Regouin-Peeters W, van Schijndel A, et al. Biological monitoring of occupational exposure to tetrachloroethene. Scand f Work Environ Health 1983;9:273-81.

5 Wilson HK. Breath analysis: physiological basis and sampling techniques. Scand $f$ Work Environ Health, 1986;12:174-192.

6 Wallace L, Buckley T, Pellizzari E, et al. Breath measurements as volatile organic compound biomarkers. Environ Health Perspect. 1996;104:861-9.

7 Smith D, Spanel P. The novel selected-ion flow tube approach to trace gas analysis of air and breath. Rapid Commun Mass Spectrom 1996;10:1183-98.

8 Smith D, Spanel P, Thompson J, et al. The selected ion flow tube method for workplace analyses of trace gases in air and breath: its scope, validation and applications. Appl Occup Environ Hyg 1998;13:817-23.

9 Lindinger W, Hansel A, Jordan A. Proton-transfer-reaction mass spectrometry (PTR-MS): on-line monitoring of volatile organic compounds at pptv levels. Chemical Society Reviews 1998;27:347-54.

10 Vreman J, Baxter LM, Stone RT, et al. Evaluation of a fully automated end-tidal carbon monoxide instrument for breath analysis. Clincial Chemistry 1996;42:50-6.

11 Health and Safety Executive. Occupational exposure limits EH40/99. London: HSE Books, 1999

12 Stepanov EV, Zyrianov PV, Khusnutdinov AN, et al. Multicomponent gas analysers based on tunable diode lasers. Proceedings of the Spie International Society for Optical Engineering 1996;2835:271-81.

13 Lukens HR. Detection of drug usage via breath analysis with an immunoassay film badge. Proceedings of the Spie International Society for Optical Engineering 1997;2932;7983.

14 Ljungkvist GM, Nordlinder RJ. A field method for sampling benzene in end-exhaled air. Am Ind Hyg Assoc f 1995;56:693-7.

15 Prado C, Tortosa JA, Ibarra I, et al. Biological monitoring of occupational exposure to isoflurance by measurement of isoflurane exhaled breath. $\mathcal{F}$ Appl Toxicol 1997;17:179-83.

16 Dyne D, Cocker J, Wilson HK. A novel device for capturing breath samples for solvent analysis. Sci Total Environ 1997; 199:83-9

17 Jones K, Akrill P, Cocker J. Breath sampling: a new dimension to personal sampling. Ann Occup Hyg 1999 (in press).

18 Non-invasive breathalyses tests for solvents. Health and Safety at Work 1999;21:68.

19 Stein VB, Narang RS, Wilson L, et al. A simple, reliable method for the determination of chlorinated volatile organics in human breath and air using glass sampling tubes. $\mathcal{F}$ Anal Toxicol 1996;20:145-50.

20 Aggazzotti G, Fantuzzi G, Righi E, et al. Blood and breath analyses as biological indicators of exposure to trihalomethanes in indoor swimming pools. Sci Total Environ 1998; 217:155-63.

21 Pleil JD, Lindstrom AB. Exhaled human breath measurement method for assessing exposure to halogenated volatile organic compounds. Clinical Chemistry 1997;43:723-30.

22 Franzblau A, Batterman S, D'Arcy JB, et al. Breath monitoring of inhalation and dermal methanol exposure. App Occup Environ Hyg 1995;10:833-9.

23 Groves WA, Zellers ET. Prototype instrument employing a microsensor array for the analysis of organic vapours in exhaled breath. Am Ind Hyg Assoc f 1996;57:1103-8.

24 Dubowski KM. Quality assurance in breath-alcohol analysis. F Anal Toxicol 1994;18:306-11.

25 American Conference of Governmental Industrial Hygienists. TLVs and BEIs, threshold limit values for chemical substances and physical agents. Cincinnati: ACGIH, 1998.

26 Deutsche Forschungsgemeinschaft. List of MAK and BAT values 1998. Weinheim: Wiley-VCH, 1998. 